\title{
Antibiotic prophylaxis for prevention of urinary tract infections in prenatal hydronephrosis: An updated systematic review
}

\author{
Bethany Easterbrook, MSc(C); John-Paul Capolicchio, MD; ${ }^{2}$ Luis H. Braga, MD, PhD
}

'McMaster Pediatric Surgery Research Collaborative, Department of Surgery, McMaster University, Hamilton, ON, Canada; ${ }^{2}$ Division of Urology, Montreal Children's Hospital, McGill University Health Centre, Montreal, QC, Canada; ${ }^{3}$ Department of Surgery, Division of Urology, McMaster University, Hamilton, ON, Canada

Cite as: Can Urol Assoc J 2017;11(1-2Suppl1):S3-11. http://dx.doi.org/10.5489/cuaj.4384

See related commentary on page S12.

\section{Abstract}

Introduction: While continuous antibiotic prophylaxis (CAP) is currently recommended to prevent urinary tract infections (UTIs) in infants with prenatal hydronephrosis $(\mathrm{HN})$, this recommendation is not evidence-based. The objective of this study was to systematically determine whether CAP reduces UTIs in the HN population. Methods: Applicable trials were identified through an electronic search of MEDLINE (1946-2015), EMBASE (1980-2016), CINAHL (1982-2016), and CENTRAL (1993-2016) and through a hand search of American Urological Association (AUA) (2012-2015) and European Society for Pediatric Urology (ESPU) (2012-2015) abstracts, as well as reference lists of included trials. The search strategy was not limited by language or year of publication. Eligible studies compared CAP to no CAP in patients with antenatal HN, $<2$ years of age, and reported development of UTI and HN grades. Two independent reviewers performed title and abstract screening, full-text review, and quality appraisal.

Results: Of 1518 citations screened, 11 were included, contributing 3909 patients for final analysis. Of these, four (36\%) were considered high-quality when assessed by the Newcastle Ottawa Scale. Meta-analysis of the non-randomized trials $(n=10)$ provided similar pooled UTI rates, regardless of CAP use: 9.9\% (95\% confidence interval [CI] 8.4-11.4\%) for CAP and 7.5\% (95\% Cl 6.4-8.6\%) for no CAP.

Conclusions: This systematic review and meta-analysis suggests there may be value in providing CAP to infants with high-grade HN; however, due to the very low-quality data from non-randomized studies, important clinical variables, such as circumcision status, were unable to be assessed.

\section{Introduction}

Prenatal hydronephrosis ( $\mathrm{HN})$ is one of the most common congenital urological anomalies, occurring in $1-5 \%$ of all pregnancies. ${ }^{1}$ Due to impaired drainage or vesico-ureteral reflux, urinary stasis may develop in patients with $\mathrm{HN}$, potentially predisposing them to an increased risk of urinary tract infections (UTIs). Approximately $8 \%$ of girls and $2 \%$ of boys will contract a UTI in the first eight years of life, with the highest incidence in both sexes occurring during the first year. ${ }^{2,3}$ Infants with $\mathrm{HN}$ are significantly more likely to develop pyelonephritis within the first year of life, ${ }^{4}$ which may lead to permanent renal damage in up to $15 \%$ of cases when compared to children without HN. ${ }^{5}$

Due to the increased risk of UTI in infants with $\mathrm{HN}$, the 2009 American Urological Association (AUA) update series on "Use of Antibiotics for Prevention and Treatment of Infections in Pediatric Urology" recommended use of continuous antibiotic prophylaxis (CAP) in this population for the first year of life; ${ }^{6}$ however, the efficacy of this treatment recommendation has been increasingly questioned over the years. This paradigm shift has occurred as recent evidence suggested that not only may CAP not reduce the risk of UTI, but it may contribute to the development of bacterial antibiotic resistance. $^{7}$ The 2009 Canadian Urological Association (CUA) guidelines on $\mathrm{HN}$ stated that the role of CAP is controversial, providing Grade D recommendation, ${ }^{8}$ while the 2009 AUA Update Series on Prenatal HN stated that although CAP was generally recommended for severe (Society of Fetal Urology [SFU] Grade III and IV) HN, this was not evidence-based. ${ }^{9}$

With growing concerns regarding the unknown longterm effects of CAP, its use for prevention of UTIs is being questioned. To date, only one systematic review and metaanalysis evaluating the effects of CAP on UTI rates in patients with $\mathrm{HN}$ has been published. ${ }^{10}$ This meta-analysis showed that there was no difference in UTI rates for patients with low-grade (SFU I-II) HN receiving CAP compared to those receiving no treatment $(2.2 \%$ vs. $2.8 \% ; \mathrm{p}=0.15)$. However, in patients with high-grade (III-IV) $\mathrm{HN}$, a significant decrease in UTI rates was observed in those receiving CAP vs. those not receiving it $(14.6 \%$ vs. $28.9 \% ; p<0.01)$. This review included single-arm observational trials, which could have skewed the pooled estimate of effect and increased the degree of heterogeneity in a field already rife with lowquality evidence. 
Due to the continued lack of best practice guidelines on this topic, we sought to update that previous systematic review examining the effectiveness of CAP in reducing UTIs in infants with prenatal $\mathrm{HN}$, analyzing this time only studies that included a direct comparison of CAP vs. no CAP. We hope that the results of this updated review will provide the necessary information to establish which $\mathrm{HN}$ patients will benefit from CAP. The upcoming 2017 CUA guidelines on $\mathrm{HN}$ will address other pertinent factors of $\mathrm{HN}$ management, such as voiding cystourethrogram (VCUG) indications, ultrasound monitoring interval, and followup duration.

\section{Methods}

\section{Selection of studies}

All articles explicitly examining the use of CAP compared to no treatment in infants with $\mathrm{HN}$ were included, with no language or date restrictions. Study population had to include male or female children $<2$ years of age who presented with prenatal $\mathrm{HN}$, classified by the SFU, ${ }^{11}$ urinary tract dilatation (UTD), ${ }^{12}$ and/or anteroposterior diameter (APD) of the renal pelvis grading systems. For the purposes of this review, SFU Grades I and II, APD 4-14.9 mm on postnatal ultrasound (US) and UTD 1 were all considered low-grade HN. High-grade HN was defined as SFU Grade III and IV, APD $\geq 15 \mathrm{~mm}$ on postnatal US, or UTD 2 and 3. Publications with insufficient information regarding CAP use, case series of $<10$ patients, animal studies, and review articles were excluded for the purposes of this review.

\section{Search methods}

The search strategy for this review involved online databases MEDLINE (1946 to present), Embase-OVID portal (1980 to present), CENTRAL (the Cochrane Central Register of Controlled Trials), and Cumulative Index to Nursing and
Allied Health Literature (CINAHL). The search strategy was devised with the assistance of a librarian and used MeSH terms when possible (Appendix A). In addition, available conference proceedings from the AUA and the European Society for Pediatric Urology (ESPU) were searched. No language restrictions were implemented and translations were obtained where necessary. Following removal of duplicates, two reviewers independently assessed titles and abstracts for study inclusion. Weighted Kappa statistic for agreement was calculated for both abstract and full-text inclusion. Disagreements regarding inclusion at both stages of study selection were resolved via discussion and consensus, with an expert.

\section{Data extraction}

Two abstractors independently extracted and evaluated data in duplicate from included studies using a previously piloted, standardized data extraction tool, with disagreements resolved by consensus. The included full-text articles were evaluated independently by two reviewers using the Newcastle-Ottawa Scale (NOS) (Table 1). ${ }^{13}$ The overall quality of evidence for primary outcomes across studies was assessed using the Grading of Recommendations Assessment, Development, and Evaluation (GRADE) system for systematic reviews. Using GRADE, the quality of evidence can be rated up or down for a variety of reasons. ${ }^{14}$

\section{Data synthesis}

Due to the anticipated heterogeneity of observational studies and small sample sizes, we a priori planned to use a random-effects model for meta-analyzing the data. ${ }^{15}$ Odds ratios $(\mathrm{OR})$ and $95 \%$ confidence intervals $(\mathrm{Cl})$ were calculated for frequency data and the Mantel-Haenszel method was used to pool effect estimates for dichotomous variables.

The primary analysis included any study that reported UTI rate stratified by CAP use, gender, vesicoureteral reflux

\begin{tabular}{|c|c|c|c|c|}
\hline Study & Selection (max. 4 stars) & Comparability (max. 2 stars) & Outcome (max. 3 stars) & Methodological quality (high >7 stars \\
\hline Braga $2016^{\dagger}$ & $* * *$ & $* *$ & $* *$ & High \\
\hline Braga 2015 & $* * *$ & ** & ** & High \\
\hline DiRenzo 2015 & $* * * *$ & -- & ** & Low \\
\hline Estrada 2009 & $* * *$ & * & ** & Low \\
\hline Gimpel 2010 & *** & -- & ** & Low \\
\hline Gokaslan 2012 & $* * *$ & -- & $*$ & Low \\
\hline Herz 2014 & $* * *$ & -- & $* *$ & Low \\
\hline Sencan 2014 & $* * *$ & -- & *** & Low \\
\hline Szymanski 2012 & $* * *$ & ** & $* *$ & High \\
\hline Zareba 2014 & $* * *$ & ** & ** & High \\
\hline Zee 2016 & $* * *$ & $*$ & $* *$ & Low \\
\hline
\end{tabular}


(VUR), circumcision status, and HN grade (high vs. low). A statistically significant difference between groups was assumed when $95 \% \mathrm{Cl}$ of the OR did not include one. Forest plots were used to graphically depict the meta-analyses for primary and secondary outcomes when appropriate.

\section{Heterogeneity and subgroup analysis}

Methodological heterogeneity was explored through conducting a priori sensitivity analyses, comparing low- vs. high-quality articles according to the NOS quality appraisal and retrospective vs. prospective data collection methods (Appendix B). Heterogeneity between studies was measured using the $\mathrm{I}^{2}$ statistic $(0-100 \%) .{ }^{15}$ Heterogeneity was also assessed informally by examining the overlap of $95 \% \mathrm{Cls}$ on forest plots. Potential sources of clinical and methodological heterogeneities that were defined a priori included: etiology (e.g., isolated $\mathrm{HN}$, primary non-refluxing megaureter, VUR), gender, HN grade (high/low), study design (prospective/retrospective), and methodological quality. Publication bias was graphically assessed through the construction of funnel plots.

\section{Results}

\section{Search strategy}

A total of 1882 results were identified through screening. Following removal of 364 duplicates, 1518 references for title and abstract review remained for assessment (Fig. 1). Ninety-five full-text articles were identified through title and abstract screening, with a weighted Kappa agreement of 0.7 (95\% Cl 0.5-0.8). Following full-text review, 10 studies were selected for inclusion in the meta-analysis, with a calculated weighted Kappa 0.9 (95\% Cl 0.7-1.0).

\section{Study characteristics}

None of the included studies were randomized clinical trials, therefore, all publications were of comparative, observational design. All articles were published in peerreviewed English journals. Four studies were conducted in Canada, ${ }^{16-19}$ four in the U.S., ${ }^{20-23}$ and one each were conducted in Germany, ${ }^{24}$ Turkey, ${ }^{25}$ and Italy. ${ }^{26} \mathrm{Six}$ studies ${ }^{16,17,20,23,25,26}$ were prospective and five $18,19,21,22,24$ retrospective. Following fulltext review, 84 articles were excluded because they were non-comparative studies, editorials, or case reports. Other reasons for exclusion included adult population, no use of CAP, or not reporting outcomes of interest. Fig. 1 includes full list of study exclusions.

\section{Quality assessment}

Four included studies were judged to be of high methodological quality ( $\geq 7$ stars), ${ }^{16-}$ 19 and seven of low quality $(<7 \text { stars })^{20-26}$ (Table 1$)$. A weighted Kappa of 0.97 (95\% Cl 0.93-1.0) was cal-
Full-text articles excluded 12 wrong outcome 17 wrong patient population 2 not antibiotic prophylaxis 12 no comparator 5 wrong intervention 2 letters to the editor

Fig. 1. PRISMA flow diagram.

Studies included in quantitative synthesis

(meta-analysis) $(n=10)$ 
Easterbrook et al.

\begin{tabular}{|c|c|c|c|c|c|c|c|c|}
\hline Study or subgroup & \multicolumn{2}{|c|}{ CAP } & \multicolumn{2}{|c|}{ No CAP } & Weight & $\begin{array}{c}\text { Odds ratio } \\
\mathrm{M}-\mathrm{H}, \text { random, } 95 \% \mathrm{Cl}\end{array}$ & \multicolumn{2}{|c|}{$\begin{array}{c}\text { Odds ratio } \\
\mathrm{M}-\mathrm{H}, \text { random, } 95 \% \mathrm{Cl}\end{array}$} \\
\hline Braga 2015 & 13 & 96 & 48 & 180 & $12.4 \%$ & $0.43(0.22,0.84)$ & -7 & \\
\hline DiRenzo 2015 & 8 & 34 & 2 & 13 & $6.9 \%$ & $1.69(0.31,9.29)$ & & \\
\hline Estrada 2009 & 5 & 322 & 16 & 1192 & $10.4 \%$ & $1.16(0.42,3.19)$ & & \\
\hline Gimpel 2010 & 13 & 30 & 13 & 14 & $5.2 \%$ & $0.06(0.01,0.51)$ & & \\
\hline Gokaslan 2012 & 14 & 58 & 9 & 78 & $11.0 \%$ & $2.44(0.97,6.11)$ & & \\
\hline Hertz 2014 & 50 & 278 & 36 & 127 & $13.3 \%$ & $0.55(0.34,0.91)$ & & \\
\hline Sencan 2014 & 2 & 369 & 21 & 323 & $8.0 \%$ & $0.08(0.02,0.34)$ & & \\
\hline Szymanski 2012 & 6 & 53 & 8 & 153 & $9.9 \%$ & $2.31(0.76,7.01)$ & & \\
\hline Zareba 2014 & 33 & 227 & 17 & 149 & $12.6 \%$ & $1.32(0.71,2.47)$ & & \\
\hline Zee 2016 & 12 & 101 & 6 & 112 & $10.4 \%$ & $2.38(0.86,6.60)$ & & \\
\hline Total (95\% CI) & & 1568 & & 2341 & $100.0 \%$ & $0.84(0.43,1,55)$ & & \\
\hline Total events & 156 & & 176 & & & & & \\
\hline \multicolumn{7}{|c|}{$\begin{array}{l}\text { Heterogeneity: } \text { Tau }^{2}=0.67 ; \mathrm{Chi}^{2}=38.64, \mathrm{df}=9(p<0.0001) ; I^{2}=77 \% \\
\text { Test for overall effect: } Z=0.46(p=0.57)\end{array}$} & 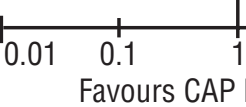 & $\begin{array}{c}10 \\
100 \\
\text { Favours No CAP }\end{array}$ \\
\hline
\end{tabular}

Fig. 2. Forest plot showing pooled estimates of urinary tract infection rates according to use of continuous antibiotic prophylaxis (CAP) (CAP vs. no CAP). Cl: confidence interval.

culated for the NOS quality appraisal agreement. All studies were classified as having moderate to high risk of bias due to methodological limitations inherent to study design. Only three studies performed multivariable analysis (binary logistic regression) to adjust for known UTI risk factors, such as gender, high-grade $\mathrm{HN}$, and circumcision status. This is problematic, as it may introduce bias into the pooled effect estimate of the meta-analysis; patients at higher baseline risk of UTI are more likely to be put on CAP.

\section{CAP and UTI}

All studies - except Braga et al 2016, which had significant patient overlap with Braga et al 2015 — were included in the meta-analyses. This resulted in 10 articles, with a total of 3909 patients, 1568 of which received CAP and 2341 who did not. Fig. 2 shows the pooled OR for CAP vs. no CAP as $0.84(95 \% \mathrm{CI} 0.45,1.55)$. The pooled UTI rate for prenatal $\mathrm{HN}$ patients receiving CAP $(9.9 \% ; 95 \% \mathrm{Cl}$ 8.4-11.4) was similar to that of $\mathrm{HN}$ patients not receiving CAP $(7.5 \% ; 95 \%$ Cl 6.4-8.6).

The significant degree of heterogeneity in this dataset, as evidenced by the $I^{2}$ of $77 \%$, was explored using subgroup analysis of high vs. low methodologic quality and prospective vs. retrospective study design (Appendix B). These subgroups did not attenuate the meta-analysis heterogeneity, which prompted a post-hoc examination of fixed-compared to random-effects analysis. This was based on the rationale that the heterogeneity was due to clinical differences in the study population (e.g., grade of HN, etiology, or gender). If the distribution of biases was roughly symmetrical, the pooled treatment effect estimate would be similar for both random- and fixed-effects models. ${ }^{26}$ Differences in the pooled UTI estimates were observed between the fixedeffects (OR $0.75 ; 95 \% \mathrm{Cl} 0.58-0.96)$ and random-effects model (OR 0.84; 95\% Cl 0.45-1.55). The fixed-effects model did not decrease the heterogeneity $\left(I^{2}=77 \%\right)$, but was in agreement with the direction and non-significance of effect.

\section{High-grade vs. low-grade HN}

A total of five studies ${ }^{16,18,19,23,25}$ reported UTI rates based on presentation of either low (I and II) or high (III and IV) SFU $\mathrm{HN}$ grade. The pooled UTI rate for high-grade $\mathrm{HN}$ was $21 \%$ (95\% Cl 17.2-24.7) compared to $10.5 \%$ (95\% Cl 8.2-12.7) for low-grade (Fig. 3). Unfortunately, adequate data was unable to be extracted to examine this association stratified by CAP use.

\section{Gender and UTI}

Four studies ${ }^{16,19,22,23}$ with a total of 1683 patients reported UTI rates according to gender. Pooled UTI rates were much higher in girls (16\%) with HN than boys (6.7\%). Data regarding gender and UTI stratified by CAP status was not available for meta-analysis (Appendix C).

\section{Circumcision status and UTI}

Circumcision status was reported in five articles ${ }^{16,18,19,22,23}$ and found to have a pooled OR of 0.24 (95\% Cl 0.12-0.50; $\mathrm{p}<0.0001)$. This provides evidence that circumcision plays a protective role against UTIs, but we were unable to assess this association with stratification by CAP use or $\mathrm{HN}$ grade, 


\begin{tabular}{|c|c|c|c|c|c|c|c|c|c|}
\hline \multirow[b]{2}{*}{ Study or subgroup } & \multicolumn{2}{|c|}{ High-grade HN } & \multicolumn{2}{|c|}{ Low-grade HN } & \multirow[b]{2}{*}{ Weight } & \multirow{2}{*}{$\begin{array}{c}\text { Odds ratio } \\
\text { M-H, random, } 95 \% \mathrm{Cl}\end{array}$} & \multirow{2}{*}{\multicolumn{3}{|c|}{$\begin{array}{c}\text { Odds ratio } \\
\text { M-H, random, } 95 \% \mathrm{Cl}\end{array}$}} \\
\hline & Events & Total & Events & Total & & & & & \\
\hline Braga 2015 & 25 & 164 & 6 & 113 & $14.1 \%$ & $3.21(1.27,8.10)$ & & & \\
\hline Gokaslan 2012 & 14 & 49 & 9 & 87 & $14.0 \%$ & $3.47(1.37,8.76)$ & & & \\
\hline Szymanski 2012 & 25 & 58 & 28 & 148 & $27.5 \%$ & $3.25(1.67,6.30)$ & & - - & \\
\hline Zareba 2014 & 25 & 128 & 25 & 248 & $33.4 \%$ & $2.17(1.19,3.95)$ & & $-\square$ & \\
\hline Zee 2016 & 7 & 49 & 9 & 138 & $11.0 \%$ & $2.39(0.84,6.81)$ & & & \\
\hline Total (95\% CI) & & 448 & & 734 & $100.0 \%$ & $2.76(1.95,3.91)$ & & & \\
\hline \multirow{3}{*}{\multicolumn{6}{|c|}{$\begin{array}{l}\text { Heterogeneity: } \text { Tau }^{2}=0.00 ; \mathrm{Chi}^{2}=1.26, \mathrm{df}=4(p<0.87) ; \mathrm{I}^{2}=0 \% \\
\text { Test for overall effect: } Z=5.73(p<0.00001)\end{array}$}} & & & & \\
\hline & & & & & & & \begin{tabular}{|ll} 
& 1 \\
0.01 & 0.1
\end{tabular} & 10 & $\overrightarrow{100}$ \\
\hline & & & & & & & Favours low-grade HN & Favours high-grac & le HN \\
\hline
\end{tabular}

Fig. 3. Forest plot showing pooled urinary tract infection (UTI) rates according to hydronephrosis (HN) grade (high vs. low). Cl: confidence interval; HN: hydronephrosis.

as this information was not reported in the included studies (Appendix C).

\section{Vesicoureteral reflux and UTI}

Appropriate data was unable to be extracted to assess the association between VUR and UTI while concurrently stratified by CAP use. However, the pooled UTI rate for infants with VUR was $12.5 \%$ compared to $4 \%$ for HN patients without VUR. This led to a pooled OR of $4.09(95 \% \mathrm{Cl}$ 1.43-11.68) (Appendix C).

\section{Discussion}

With the increasingly vocal scrutiny of antibiotic use due to concerns regarding long-term adverse effects and bacterial resistance, we sought to summarize current evidence regarding the use of CAP in $\mathrm{HN}$ patients. When interpreting the findings of this systematic review, it is important to keep in mind factors such as grade and etiology of $\mathrm{HN}$, gender, VUR status, and circumcision status most likely affected the indication for CAP in these observational studies. As a result, analysis of UTI rates based on CAP status was subjected to bias.

We included 10 studies of infants with prenatal HN, which were all conducted in developed countries. All studies reported the proportion of patients on CAP and the number of UTIs in both the treatment (CAP) and no treatment groups. Unfortunately, data regarding CAP use stratified by gender, circumcision status, VUR, and high- vs.low-grade HN were missing. This made it impossible to accurately perform the pre-planned subgroup analyses. Ideally, patient-level data will be obtained in order to perform a meta-regression for exploration of these baseline differences. Nevertheless, in order to use the data extracted from the included studies, overall UTI rates within these subgroups were still analyzed (Appendix C). The overall effect of CAP on UTIs in patients with HN provided an OR of 0.84 (95\% Cl 0.45-1.55). While this was not statistically significant, as it crossed the measure of no effect, it could indicate a slight protective effect of CAP against UTIs in this population. However, high-level evidence in the form of randomized, controlled trials is needed to determine if this potentially protective effect is true or simply spurious.

\section{Quality of evidence}

The quality of evidence assessment was performed using GRADE. Evidence for CAP vs. no CAP on UTI rates was downgraded for risk of bias due to the intrinsic methodological limitations of the included observational studies and for inconsistency of results because of high heterogeneity that, due to incomplete data, we were unable to definitively explain by a priori subgroups (Table 2).

Evidence was not downgraded for risk of publication bias, as large effect studies were missing, but small effect studies were equally distributed on either side of the funnel plot.

\section{Limitations}

While this review provides further proof of the need for high-quality evidence in this field, it does have important limitations. First, this review was limited by the low quality of evidence generated by only reviewing observational studies. The fact that there were no randomized, controlled trials found in this systematic search, and that the majority of the included studies were of low quality, accurately reflects the current state of the literature on prenatal $\mathrm{HN}$. Another limitation stems from the inability to comment on any associations between CAP use and gender, VUR status, $\mathrm{HN}$ grade, and circumcision status.

As female gender, uncircumcised males, those with high-grade $\mathrm{HN}$ and VUR, and patients not receiving CAP were shown, both previously and in this review, to have 
Easterbrook et al.

higher risk of UTI than their counterparts, it is prudent to offer CAP to infants with these characteristics until properly power, high-methodological-quality studies confirm or refute these findings.

\section{Future directions}

The very low-quality evidence generated by this review and the inability of a systematic search to find any randomized, controlled trials on the subject suggest the importance of conducting high-quality research on CAP for prenatal $\mathrm{HN}$ patients. More studies on this topic will likely alter the pooled-effect estimate of this meta-analysis and, in turn, have the potential to affect the clinical management of these patients. While this review provides us with a broad basis as to whether CAP may be effective in infants with more severe grades (SFU III and IV) of HN, future studies should focus on ensuring that all pertinent data regarding population characteristics are collected for analysis, so that stratification based on risk factors can occur.

\section{Conclusion}

This systematic review suggests that CAP may have a slight, but statistically insignificant, protective effect against UTI rates in infants with prenatal HN. However, due to the very low quality of the evidence and many study limitations, this conclusion must be interpreted with extreme caution. The lack of definitive guidelines in pediatric urology, coupled with the deficits in the current literature provide ample evidence of the necessity of high-quality, randomized, placebo-controlled trials investigating the effects of CAP in this population.

Competing interests: The authors report no competing personal or financial interests.

This paper has been peer-reviewed.

\section{References}

1. Woodward M, Frank D. Postnatal management of antenatal hydronephrosis. BJU Int 2002;89:149-56. https://doi.org/10.1046/j.1464-4096.2001.woodward.2578.x

2. Montini G, Tullus K, Hewitt I. Febrile urinary tract infections in children. N Engl J Med 2011;365:239-50. https://doi.org/10.1056/NEJMra1007755

3. Marild $S$, Jodal U. Incidence rate of first-time symptomatic urinary tract infection in children under six years of age. Acta Paediatr 1998;87:549-52. https://doi.org/10.1111/i.1651-2227.1998.tb01502.x

4. Walsh TJ, Hsieh S, Grady R, et al. Antenatal hydronephrosis and the risk of pyelonephritis hospitalization during the first year of life. Urology 2007 69:970-4. https://doi.org/10.1016/i.urology.2007.01.062

5. Shaikh N, Ewing AL, Bhatnagar $S$, et al. Risk of renal scarring in children with a first urinary tract infection: A systematic review. Pediatrics 2010;126:1084-91. htrps://doi.org/10.1542/peds.2010-0685

6. Hollowell JG, Cunnion K. Use of antibiotics for prevention and treatment of infections in pediatric urology. AUA Update Series 2009:8:33-40.

7. Williams GJ, Wei L, Lee A, et al. Long-term antibiotics for preventing recurrent urinary tract infection in children. Cochrane Database Syst Rev 2006;19:CD001534. https://doi.org/10.1002/14651858. cd001534.pub2

8. Psooy K. Canadian Urological Association guidelines on antenatal hydronephrosis. Can Urol Assoc J 2009;1:69-72.

9. Herndon ACD, Cain MP. AUA Update Series Lesson 3, 2009; 28 Prenatal Diagnosis of Urological Disease.

10. Braga $L H$, Mijovic $H$, Farrokhyar $F$, et al. Antibiotic prophylaxis for urinary tract infections in antenatal hydronephrosis. Pediatrics 2013;131:251-61. https://doi.org/10.1542/peds.2012-1870

11. Fernbach SK, Maizels M, Conway JJ. Ultrasound grading of hydronephrosis: Introduction to the system used by the Society for Fetal Urology. Pediatr Radiol 1994;23:478-80. https://doi.org/10.1007/ BF02012459

\section{Table 2. Antibiotic prophylaxis compared to no treatment for urinary tract infection in hydronephrosis}

\begin{tabular}{|c|c|c|c|c|}
\hline $\begin{array}{l}\text { Outcome } \\
\text { No. of participants (studies) }\end{array}$ & $\begin{array}{l}\text { Relative effect } \\
\text { (95\% Cl) }\end{array}$ & Antic & pated absolute & fects $(95 \% \mathrm{CI})$ \\
\hline & & Without CAP & With CAP & Difference \\
\hline $\begin{array}{l}\text { UTI } \\
3909\end{array}$ & $\begin{array}{c}\text { OR } 0.84 \\
(0.45-1.55)\end{array}$ & Low & & \\
\hline & & $10.0 \%$ & $\begin{array}{c}85 \text { per } 1000 \\
(48-147)\end{array}$ & $\begin{array}{c}15 \text { fewer per } 1000 \\
\text { (52 fewer-47 more) }\end{array}$ \\
\hline & & Moderate & & \\
\hline & & $20.0 \%$ & $\begin{array}{l}174 \text { per } 1000 \\
(101-279)\end{array}$ & $\begin{array}{l}26 \text { fewer per } 1000 \\
\text { (99 fewer-79 more) }\end{array}$ \\
\hline & & High & & \\
\hline & & $30.0 \%$ & $\begin{array}{l}265 \text { per } 1000 \\
(162-399)\end{array}$ & $\begin{array}{c}35 \text { fewer per } 1000 \\
(138 \text { fewer-99 more) }\end{array}$ \\
\hline
\end{tabular}

Quality What hapens

Very low

GRADE Working Group grades of evidence:

High-quality: We are very confident that the true effect lies close to that of the estimate of the effect.

Moderate-quality: We are moderately confident in the effect estimate. The true effect is likely to be close to the estimate of the effect, but there is a possibility that it is substantially different.

Low-quality: Our confidence in the effect estimate is limited. The true effect may be substantially different from the estimate of effect. Very-low-quality: We have very little confidence in the effect estimate. The true effect is likely to be substantially different from the estimate of effect.

Patient or population: UTI in hydronephrosis (HN); setting: prenatal HN; intervention: antibiotic prophylaxis; comparison: no treatment. The risk in the intervention group (and its $95 \%$ Cl) is based on the assumed risk in the comparison group and the relative effect of the intervention (and its $95 \% \mathrm{Cl}$ ). Cl: confidence interval; OR: odds ratio. 
12. Nguyen $\mathrm{HT}$, Benson $\mathrm{CB}$, Bromley $\mathrm{B}$, et al. Multidisciplinary consensus on the classification of prenatal and postnatal urinary tract dilation (UTD classification system). J Ped Urol 2014;10:982-98. https://doi.org/10.1016/i.jpurol.2014.10.002

13. Wells $G$, Shea B, O'Connell D, et al. The Newcastle-Ottawa Scale (NOS) for assessing the quality of nonrandomised studies in meta-analyses. Ottawa: Ottawa Hospital Research Institute; 2009. www.ohri. ca/programs/clinical_epidemiology/oxford.asp. Accessed December 29,2016.

14. GRADE Working Group. Grading quality of evidence and strength of recommendations. BMJ 2004;328:1490. https://doi.org/10.1136/bmi.328.7454.1490

15. Higgins J. Green S Cochrane Handbook for Systematic Reviews of Interventions. Version 5.1.0 [updated March 2011].The Cochrane Collaboration, 2011. 2011.

16. Braga LH, Farrokhyar F, D'Cruz J, et al. Risk factors for febrile urinary tract infection in children with prenatal hydronephrosis: A prospective study. J Urol 2015:193:1766-71. https://doi.org/10.1016/i. juro.2014.10.091

17. Braga LH, $D^{\prime}$ Cruz J, Rickard $M$, et al. The fate of primary non-refluxing megaureter: A prospective outcome analysis on the rate of urinary tract infections, surgical indications and time to resolution. J Urol 2016;195(4 Pt 2):1300-5. https://doi.org/10.1016/i.juro.2015.11.049

18. Szymanski KM, Al-Said AN, Salle JLP, et al. Do infants with mild prenatal hydronephrosis benefit from screening for vesicoureteral reflux? J Urol 2012:188:576-81. https://doi.org/10.1016/i. juro.2012.04.017

19. Zareba P, Lorenzo AJ, Braga LH. Risk factors for febrile urinary tract infection in infants with prenatal hydronephrosis: Comprehensive, single-centre analysis. J Urol 2014: 91:1614-9. https://doi.org/10.1016/i. juro.2013.10.035

20. Estrada $C R$, Peters $C A$, Retik $A B$, et al. Vesicoureteral reflux and urinary tract infection in children with a history of prenatal hydronephrosis — should voiding cystourethrography be performed in cases of postnatally persistent Grade II hydronephrosis? J Urol 2009:181:801-7. https://doi.org/10.1016/i. juro.2008.10.057

21. Herz D, Merguerian P, McQuiston L. Continuous antibiotic prophylaxis reduces the risk of febrile UTI in children with asymptomatic antenatal hydronephrosis with either ureteral dilation, high-grade vesicoureteral reflux, or ureterovesical junction obstruction. J Pediatr Urol 2014;10:650. https://doi.org/10.1016/i. ipurol.2014.06.009

22. Sencan A, Carvas F, Hekimoglu IC, et al. Urinary tract infection and vesicoureteral reflux in children with mild antenatal hydronephrosis. J Pediatr Urol 2014;10:1008. https://doi.org/10.1016/i. ipurol.2014.04.001

23. Zee RS, Herbst KW, Kim C, et al. Urinary tract infections in children with prenatal hydronephrosis: A risk assessment from the Society for Fetal Urology hydronephrosis registry. J Pediatr Urol 2016;12:261 .el-7. https://doi.org/10.1016/i.jpurol.2016.04.024

24. Gimpel C, Masioniene L, Djakovic N, et al. Complications and long-term outcome of primary obstructive megaureter in childhood. Pediatr Nephrol 2015;25:1679-86. https://doi.org/10.1007/s00467-0101523-0

25. Gökaslan F, Yalcinkaya F, Fitoz $S$, et al. Evaluation and outcome of antenatal hydronephrosis: A prospective study. Renal Failure 2012;34:718-21. https://doi.org/10.3109/0886022X.2012.676492

26. DiRenzo D, Persico $A$, DiNicola $M$, et al. Conservative management of primary non-refluxing megaureter during the first year of life: A longitudinal observational study. J Pediatr Urol 2015;11:226.

Correspondence: Dr. Luis H. Braga, Department of Surgery, Division of Urology, McMaster University, Hamilton, 0N, Canada; braga@memaster.ca

\section{Appendix A. Search strategy for MEDLINE}

(Database: Ovid MEDLINE(R) In-Process \& other non-indexed citations, Ovid MEDLINE(R) Daily and Ovid MEDLINE(R) $<1946$ to present>)

\section{Search strategy:}

1. Antibiotic Prophylaxis/ (11044)

2. exp Anti-Infective Agents/ (1374443)

3. (antibiotic* or antibacterial* or anti-infective ${ }^{*}$ ).mp. [mp=title, abstract, original title, name of substance word, subject heading word, keyword heading word, protocol supplementary concept word, rare disease supplementary concept word, unique identifier] (374143)

4. (amoxicillin or penicillin or trimethoprim).mp. [mp=title, abstract, original title, name of substance word, subject heading word, keyword heading word, protocol supplementary concept word, rare disease supplementary concept word, unique identifier] (89855)

5. antibacterial agents.mp. (4469)

6. 1 or 2 or 3 or 4 or 5 (1512509)

7. exp Urinary Tract Infections/ (40657)

8. ((urin* or bladder) adj3 infection*).mp. (51150)

9. UTI.mp. (6402)

10. pyuria.mp. (2055)

11. bacterimia.mp. (6)

12. bacteremia.mp. (30685)

13. febrile urinary infection*.mp. (20)

14. or/7-13 (87516)

15. exp Hydronephrosis/ (9954)

16. hydronephros*.mp. (14226)

17. vesico-ureteral reflux.mp. (7817)

18. vesicoureteral reflux/ (7615)

19. renal pelvic dilatation.mp. (78)

20. renal pelvis dilatation.mp. (61)

21. utereral obstruction.mp. (0)

22. ureter obstruction/ (0)

23. uteropelvic junction obstruction.mp. or ureteropelvic junction obstruction/ (1)

24. megaureter.mp. or megaureter/ (766)

25. primary nonrefluxing megaureter.mp. (7)

26. dilated ureter.mp. (168)

27. renal dilation.mp. (17)

28. renal dilatation.mp. (30)

29. pyelonephritis.mp. (17663)

30. pyonephros*.mp. (600)

31. or/15-30 (37786)

32. Prenatal Diagnosis/ (32510)

33. antenatal.mp. (25902)

34. fetal.mp. (310894)

35. newborn.mp. (650900)

36. neonatal.mp. (178829)

37. infant.mp. (1031626)

38. (prenatal or antenatal).mp. [mp=title, abstract, original title, name of substance word, subject heading word, keyword heading word, protocol supplementary concept word, rare disease supplementary concept word, unique identifier] (152206)

39. or/32-38 (1458139)

40. 6 and 14 and 31 and 39 (717) 
Easterbrook et al.

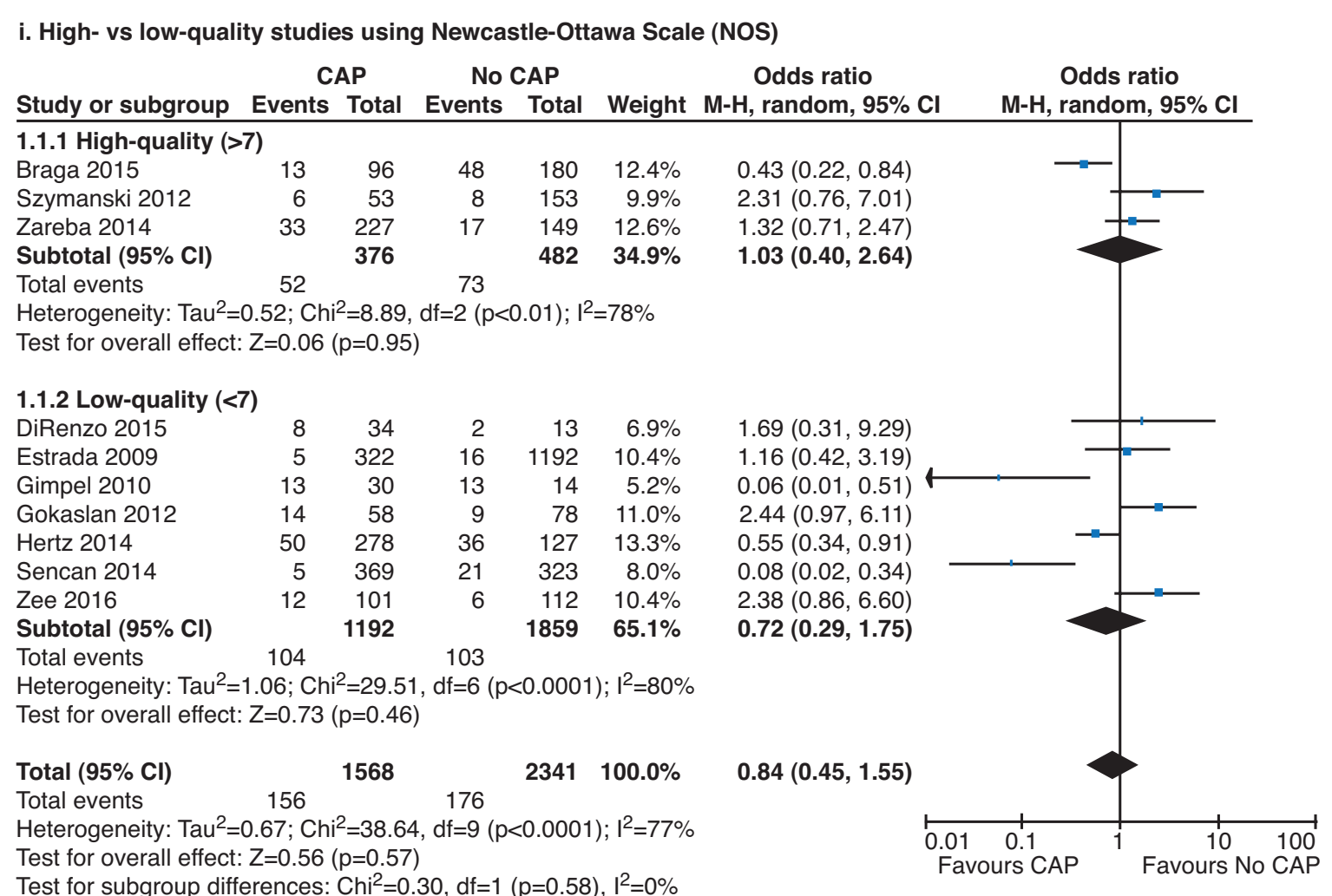

ii. Prospective vs. retrospective study design

CAP No CAP

Odds ratio

Odds ratio

Study or subgroup Events Total Events Total Weight $\mathrm{M}-\mathrm{H}$, random, $95 \% \mathrm{Cl} \quad \mathrm{M}-\mathrm{H}$, random, $95 \% \mathrm{Cl}$

7.1.1 Retrospective

Gimpel 2010

Hertz 2014

$13 \quad 30$

$30 \quad 13$

$\begin{array}{rrr}13 & 14 & 5.2 \% \\ 36 & 127 & 13.3 \%\end{array}$

$\begin{array}{rr}127 & 13.3 \% \\ 323 & 8.0 \%\end{array}$

Sencan 2014

Szymanski 2012

369

36

$8.0 \%$

653

21
8

153

$12.6 \%$

$766 \quad 49.0 \%$

Subtotal $(95 \% \mathrm{Cl})$

957

$49.0 \%$

$\begin{array}{lcc}\text { Total events } & 104 & 95 \\ \text { Heterogeneity: } \text { Tau }^{2}=1.00 ; \mathrm{Chi}^{2}=23.84, \mathrm{df}=4(p<0.0001) & \mathrm{I}^{2}=83 \%\end{array}$

Heterogeneity: Tau $^{2}=1.00 ; \mathrm{Chi}^{2}=23.84$
Test for overall effect: $Z=1.35(\mathrm{p}=0.18)$

\subsubsection{Prospective}

Braga 2015

DiRenzo 2015

Estrada 2009

Gokaslan 2012

Zee 2016

Subtotal $(95 \% \mathrm{Cl})$

$\begin{array}{rr}13 & 96 \\ 8 & 34 \\ 5 & 322 \\ 14 & 58 \\ 12 & 101 \\ & 611\end{array}$

$96 \quad 48$

34

322

2

$180 \quad 12.4 \%$

$0.43(0.22,0.84)$

$1.69(0.31,9.29)$

$1.16(0.42,3.19)$

$2.44(0.97,6.11)$

$2.38(0.86,6.60)$

$611 \quad 1575 \quad 51.0 \% \quad 1.29(0.58,2.87)$

Total events

52

81

$0.06(0.01,0.51)$

$0.08(0.02,0.34)$

(0.76, 7.01)

$0.50(0.18,1.38)$

Heterogeneity: $\mathrm{Tau}^{2}=0.54 ; \mathrm{Chi}^{2}=12.83, \mathrm{df}=4(\mathrm{p}=0.01) ; \mathrm{I}^{2}=69 \%$

Test for overall effect: $Z=0.63(p=0.53)$

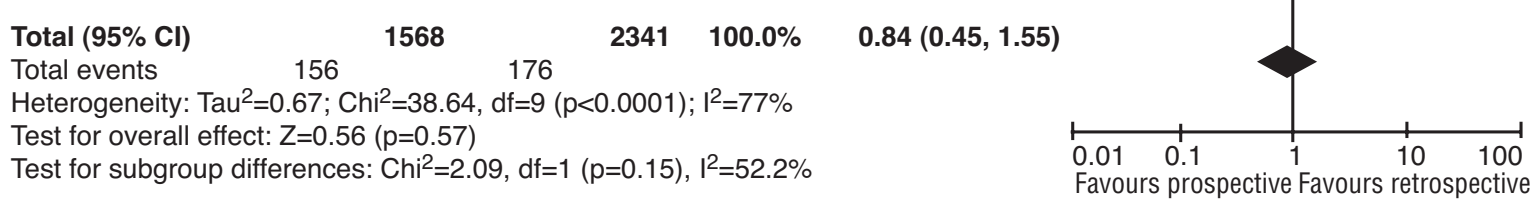

Appendix B. Sensitivity analysis for continuous antibiotic prophylaxis (CAP) and urinary tract infection (UTI) heterogeneity. Cl: confidence interval. 


\begin{tabular}{|c|c|c|c|c|c|c|c|c|}
\hline \multicolumn{9}{|c|}{ i. Forest plot of UTI rates according to presence of VUR or not } \\
\hline \multirow[b]{2}{*}{ Study or subgroup } & \multicolumn{2}{|c|}{ VUR } & \multicolumn{2}{|c|}{ No VUR } & \multirow[b]{2}{*}{ Weight } & Odds ratio & \multirow{2}{*}{\multicolumn{2}{|c|}{$\begin{array}{l}\text { Odds ratio } \\
\mathrm{M}-\mathrm{H} \text {, random, } 95 \% \mathrm{Cl}\end{array}$}} \\
\hline & Events & Total & Events & Total & & $\mathrm{M}-\mathrm{H}$, random, $95 \% \mathrm{Cl}$ & & \\
\hline Braga 2015 & 34 & 57 & 27 & 219 & $22.6 \%$ & $10.51(5.41,20.44)$ & & -1 \\
\hline Estrada 2009 & 5 & 322 & 16 & 1192 & $20.2 \%$ & $1.16(0.42,3.19)$ & & \\
\hline Sencan 2014 & 2 & 13 & 21 & 679 & $16.0 \%$ & $5.70(1.19,27.33)$ & & \\
\hline Szymanski 2012 & 6 & 17 & 8 & 189 & $18.6 \%$ & $12.34(3.64,41.84)$ & & \\
\hline Zareba 2014 & 14 & 79 & 36 & 297 & $22.6 \%$ & $1.56(0.80,3.07)$ & & \\
\hline \multicolumn{2}{|l|}{ Total $(95 \% \mathrm{Cl})$} & 488 & \multicolumn{4}{|c|}{$2576100.0 \% 4.09(1.43,11.68)$} & & \\
\hline Total events & 61 & & 108 & & & & \multirow[b]{2}{*}{ 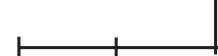 } & \\
\hline \multicolumn{7}{|c|}{ Heterogeneity: $\operatorname{Tau}^{2}=1.15 ; \mathrm{Chi}^{2}=25.01, \mathrm{df}=4(p<0.0001) ;\left.\right|^{2}=84 \%$} & & \\
\hline \multicolumn{7}{|c|}{ Test for overall effect: $Z=2.63(p=0.009)$} & \multicolumn{2}{|c|}{ 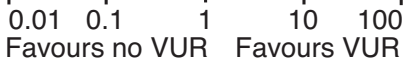 } \\
\hline \multicolumn{9}{|c|}{ ii. Forest plot of pooled UTI rates according to gender } \\
\hline \multirow[b]{2}{*}{ Study or subgroup } & \multicolumn{2}{|c|}{ Female } & \multicolumn{2}{|c|}{ Male } & \multirow[b]{2}{*}{ Weight } & \multirow{2}{*}{$\begin{array}{l}\text { Odds ratio } \\
\mathrm{M}-\mathrm{H} \text {, random, } 95 \% \mathrm{Cl}\end{array}$} & \multirow{2}{*}{\multicolumn{2}{|c|}{$\begin{array}{c}\text { Odds ratio } \\
\mathrm{M}-\mathrm{H} \text {, random, } 95 \% \mathrm{Cl}\end{array}$}} \\
\hline & Events & Total & Events & Total & & & & \\
\hline Braga 2015 & 25 & 73 & 40 & 261 & $31.6 \%$ & $2.88(1.60,5.19)$ & & 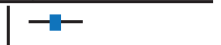 \\
\hline Sencan 2014 & 8 & 152 & 15 & 608 & $22.4 \%$ & $2.20(0.91,5.28)$ & & \\
\hline Zareba 2014 & 15 & 99 & 27 & 277 & $28.5 \%$ & $1.65(0.84,3.26)$ & & \\
\hline Zee 2016 & 13 & 59 & 5 & 154 & $17.6 \%$ & $8.42(2.85,24.88)$ & & \\
\hline Total $(95 \% \mathrm{Cl})$ & & 383 & & 1300 & $100.0 \%$ & $2.79(1.58,4.95)$ & & \\
\hline \multirow{2}{*}{\multicolumn{6}{|c|}{$\begin{array}{l}\text { Heterogeneity: } \text { Tau }^{2}=0.18 ; \mathrm{Chi}^{2}=6.49, \mathrm{df}=3(p=0.09) ; \mathrm{I}^{2}=54 \% \\
\text { Test for overall effect: } Z=3.52(p=0.0004)\end{array}$}} & & & \\
\hline & & & & & & & $\begin{array}{ll}0.01 & 0.1 \\
\text { Favours male }\end{array}$ & $\begin{array}{l}1 \\
\text { Favours female }\end{array}$ \\
\hline
\end{tabular}

Appendix C. Forest plots of urinary tract infection (UTI) rates according to gender and vesicoureteral reflux (VUR). Cl: confidence interval. 